\title{
Mitochondrial Flashes: Dump Superoxide and Dance with Protons Now
}

\author{
Nicolas Demaurex ${ }^{1}$ and Markus Schwarzländer ${ }^{2}$
}

\begin{abstract}
Transient changes in the physiology of individual mitochondria have recently drawn much interest. The use of a circular permuted yellow fluorescent protein (cpYFP) to monitor mitochondrial flashes and their interpretation as superoxide bursts has added confusion, however. Reviewing mitochondrial flashes in this Forum, Wang et al. again deem cpYFP to be a specific and reversible superoxide indicator, dismissing evidence that purified cpYFP is insensitive to superoxide. This interpretation lacks reproducible evidence and conflicts with the parsimony principle. We offer a constructive, transparent pathway to reach definitive clarification of contradictory reports. Antioxid. Redox Signal. 25, 550-551.
\end{abstract}

\section{Dear Editor:}

$\mathbf{E}$ XTRAORDINARY CLAIMS REQUIRE extraordinary evidence (1). Claiming that a fluorescent protein is selectively and reversibly modified by superoxide and reports "superoxide $\mathrm{fla}$ shes" in living tissues as Wang et al. reiterate in this Forum (4), is extraordinary. Unfortunately the evidence is quite ordinary.

A molecular mechanism of superoxide sensitivity is lacking and chemically implausible given the absence of free-radical traps and supporting structural data. Direct experimental evidence for superoxide sensitivity is limited to a few fluorescence spectra of purified recombinant circular permuted yellow fluorescent protein (cpYFP), showing approximately twofold increase upon oxygenation and another approximately twofold after subsequent addition of a superoxide-generating system unless superoxide dismutase is present (3). The $\mathrm{pH}, \mathrm{pO}_{2}$, redox potential, and structural states of cpYFP before and after oxygenation and superoxide generation were not measured.

Scientific experiments must be reproducible. In no instance has the fluorescence response of purified cpYFP to superoxide been reproduced independently. In our hands, the spectroscopic properties of cpYFP are insensitive to oxidants regardless of $\mathrm{pH}$, atmospheric composition, incubation time, and reducing pretreatment. Instead, cpYFP showed highly $\mathrm{pH}$-sensitive, redox-resistant fluorescence (2). Wang et al. attribute this disconnect (5) to potential differences in cpYFP sequence and Escherichia coli strains, although sequence identity was verified and several strains consistently gave negative results. Their superoxide assay starts after oxygenation, yet they insist that cpYFP must be fully reduced to reveal its response to oxidation and superoxide (5), implying that a protein reversibly and repeatedly modified by superoxide in cells must be fully reduced to reveal its superoxide sensitivity when purified. The disturbing truth is that in $>8$ years, nobody has been able to obtain graded and reversible cpYFP responses to superoxide. The extraordinary evidence is lacking and the ordinary evidence is not reproducible.

Wang et al. initially dismissed any $\mathrm{pH}$ contribution to cpYFP flashes despite reporting $\sim 10$-fold cpYFP fluorescence increase between neutral and alkaline $\mathrm{pH}$ [see Fig. S1f in Ref. (3)]. They now reinterpret cpYFP flashes as multifaceted signals including a superoxide or ROS signal and an alkalinisation signal (5). This belatedly acknowledges flashes as $\mathrm{pH}$ events but adds new confusion by blending the invisible superoxide with undefined reactive oxygen species

\footnotetext{
${ }^{1}$ Department of Cell Physiology and Metabolism, University of Geneva, Geneva, Switzerland.

${ }^{2}$ Plant Energy Biology Lab, Department Chemical Signalling, Institute of Crop Science and Resource Conservation (INRES), University of Bonn, Bonn, Germany.

(C) Nicolas Demaurex and Markus Schwarzländer 2016; Published by Mary Ann Liebert, Inc. This Open Access article is distributed under the terms of the Creative Commons Attribution Noncommercial License (http://creativecommons.org/licenses/by-nc/4.0/) which permits any noncommercial use, distribution, and reproduction in any medium, provided the original author(s) and the source are credited.
} 
(ROS), despite their evidence that cpYFP fluorescence is unaffected by various reactive species (3). It is likely that $\mathrm{pH}$ flashes affect mitochondrial ROS dynamics, but this cannot be assessed with probes blind to reactive species.

Mitochondrial flashes are fascinating biological events. But to understand their origin we must know what we measure. The review by Wang et al. rehashes a controversy causing researchers to misuse the sensor and to misinterpret flashes. Although the burden of proof lies with the claimants of the extraordinary, we offer our constructive help to jointly test the explicit hypothesis that mature, purified cpYFP can respond to the acute generation of superoxide in vitro by a pronounced change of its fluorescence properties, in a rapid, rapidly reversible, specific, and reproducible manner. The yes/no outcome of these experiments, performed under each other's rigorous supervision, must be reported transparently.

\section{References}

1. Laplace PS. Extraordinary claims require extraordinary evidence, for the claimants might deceive or be deceived, and the probability that these two causes are true is inversely proportional to the reality of the fact itself [in French]. Théorie analytique des probabilités. Paris, Bruxelles: Culture et civilisation, 1812, p. 464.

2. Schwarzländer M, Wagner S, Ermakova YG, Belousov VV, Radi R, Beckman JS, Buettner GR, Demaurex N, Duchen MR, Forman HJ, Fricker MD, Gems D, Halestrap AP, Halliwell B, Jakob U, Johnston IG, Jones NS, Logan DC, Morgan B, Muller FL, Nicholls DG, Remington SJ, Schumacker PT, Winterbourn CC, Sweetlove LJ, Meyer AJ, Dick TP, and Murphy MP. The 'mitoflash' probe cpYFP does not respond to superoxide. Nature 514: E12-E14, 2014.

3. Wang W, Fang H, Groom L, Cheng A, Zhang W, Liu J, Wang X, Li K, Han P, Zheng M, Yin J, Wang W, Mattson MP, Kao JP, Lakatta EG, Sheu SS, Ouyang K, Chen J, Dirksen RT, and Cheng H. Superoxide flashes in single mitochondria. Cell 134: 279-290, 2008.
4. Wang W, Gong G, Wang X, Wei-LaPierre L, Cheng H, Dirksen RT, and Sheu SS. Mitochondrial flash: integrative ROS and $\mathrm{pH}$ signals in cell and organelle biology. Antioxid Redox Signal 25: 534-549, 2016.

5. Wang W, Zhang H, and Cheng H. Mitochondrial flashes: from indicator characterization to in vivo imaging. Methods 2016 [Epub ahead of print]; DOI: 10.1016/j.ymeth.2016.06.004.

Address correspondence to:

Dr. Nicolas Demaurex

Department of Cell Physiology and Metabolism

University of Geneva

1, rue Michel-Servet

Geneva $4 \mathrm{CH}-1211$

Switzerland

E-mail: nicolas.demaurex@unige.ch

Dr. Markus Schwarzländer

Plant Energy Biology Lab

Department Chemical Signalling Institute of Crop Science and Resource

Conservation (INRES) University of Bonn

Friedrich-Ebert-Allee 144

Bonn 53113

Germany

E-mail: markus.schwarzlander@uni-bonn.de

Date of first submission to ARS Central, July 9, 2016; date of acceptance, July 11, 2016.

Abbreviations Used
$\mathrm{cpYFP}=$ circular permuted yellow fluorescent protein
ROS $=$ reactive oxygen species

